\title{
Identification and characterization of in vivo, in vitro and reactive metabolites of vandetanib using LC-ESI-MS/MS
}

\author{
Mohamed W. Attwa ${ }^{1,2^{*}}$, Adnan A. Kadi ${ }^{1}$, Hany W. Darwish ${ }^{1,2}$, Sawsan M. Amer ${ }^{2}$ and Nasser S. Al-shakliah ${ }^{1}$
}

\begin{abstract}
Vandetanib (Caprelsa tablets, VNT) is an orally inhibitor of vascular endothelial growth factor receptor 2 . The current research reports the characterization and identification of in vitro, in vivo and reactive intermediates of VNT. In vitro metabolites of VNT were performed by incubation with rat liver microsomes (RLMs). Extraction of vandetanib and its in vitro metabolites from the incubation mixtures were done by protein precipitation. In vivo metabolism was done by giving one oral dose of vandetanib $(30.8 \mathrm{mg} / \mathrm{kg}$ ) to Sprague Dawley rats in metabolic cages by using oral gavage. Urine was gathered then filtered at certain time intervals $(0,6,12,18,24,48,72,96$ and $120 \mathrm{~h}$ ) from vandetanib dosing. A similar volume of ACN was added to each collected urine sample. Both layers (organic and aqueous) were injected into liquid chromatography electro spray ionization tandem mass spectrometry (LC-ESI-MS/MS) to detect in vivo vandetanib metabolites. $\mathrm{N}$-methyl piperidine ring of vandetanib is considered a cyclic tertiary amine that undergoes metabolism forming iminium intermediates that are very reactive toward nucleophilic macromolecules. Incubation of vandetanib with RLMs in the presence of $1.0 \mathrm{mM} \mathrm{KCN}$ was made to check reactive metabolites as it is usually responsible for noticeable idiosyncratic toxicities including phototoxicity and QT interval prolongation. Four in vivo phase I, one in vivo phase II metabolites, six in vitro phase I metabolites and four cyano conjugates of vandetanib were detected by LC-MS/MS. In vitro and in vivo phase I metabolic reactions were $\mathrm{N}$-oxide formation, $\mathrm{N}$-demethylation, a-carbonyl formation and a-hydroxylation. In vivo phase II metabolic reaction was direct conjugation of vandetanib with glucuronic acid. All metabolic reactions occurred in $\mathrm{N}$-methyl piperidine of vandetanib which causes toxicity and instability of vandetanib.
\end{abstract}

Keywords: $\mathrm{N}$-methyl piperidine, Vandetanib, In vivo metabolites, In vitro metabolites, Cyano conjugates

\section{Introduction}

Vandetanib (ZD6474) is an available orally inhibitor of vascular endothelial growth factor receptor 2 (VEGFR) [1]. VEGFR has gained great importance as pharmacologic targets as a Tyrosine kinase receptors [2]. Vandetanib, on 6 April 2011, was approved by the FDA for the treatment of patients suffered from symptomatic or progressive medullary thyroid cancer with unresectable, locally advanced, or metastatic disease. It was considered the first drug approved for this case. The trade name of

\footnotetext{
*Correspondence: mzeidan@ksu.edu.sa; chemistzedan@yahoo.com ${ }^{1}$ Department of Pharmaceutical Chemistry, College of Pharmacy, King Saud University, P.O. Box 2457, Riyadh 11451, Kingdom of Saudi Arabia Full list of author information is available at the end of the article
}

vandetanib was Caprelsa tablets (AstraZeneca Pharmaceuticals LP). Sudden death and QT prolongation of the are severe side effects for vandetanib [3].

Metabolism is detoxification process of xenobiotics and endogenous compounds by transforming into more hydrophilic compounds to allow excretion outside the body. Drug metabolism work is an essential step in the process of drug discovery, and is usually the factor that evaluate the degree of given drug success to take the approval and to reach the market [4]. Drug metabolism research is done through in vitro and in vivo techniques. In vivo metabolism was performed through the single dose administration of vandetanib to rat using oral gavage followed by gathering of urine samples, at specific time intervals, that contain the 
drugs and their possible metabolites. In vitro techniques include drugs incubation with various types of in vitro preparations (e.g. hepatocytes and liver microsomes) separated from rats then sample processing and analysis using chromatographic techniques.

Phase I metabolism either in vitro or in vivo of cyclic tertiary amines generates oxidative metabolites including: $\alpha$-carbonyl formation, ring opening metabolites, $\mathrm{N}$-oxygenation, ring hydroxylation and $\mathrm{N}$-dealkylation. Metabolites are often less toxic than parent molecules, but occasionally undergo bioactivation forming unstable reactive intermediates that considered more toxic in comparison to parent molecules [5-7]. Reactive metabolites can covalently bind to proteins, which is considered the initiating step in the process of druginduced organ toxicities $[8,9]$.

$N$-methyl piperidine ring is a part of vandetanib chemical structure that is considered a cyclic tertiary amine. Drugs that contain cyclic tertiary amine group are able to form iminium intermediates which are hard nucleophiles [10-12]. GSH or its derivatives are not the appropriate as capturing agent for hard nucleophiles while potassium cyanide $(\mathrm{KCN})$ is the best agent for trapping these reactive intermediate including iminium ion_ENREF_7 [5] resulted in stable adducts formation which can be characterized, separated and detected using LC-MS/MS [13, 14].

Since bioactivation is often considered the central reason for observed side effects including phototoxicity and prolongation of QT interval $[3,15]$, we tested the reactive metabolites formation by incubation of vandetanib with $1.0 \mathrm{mM} \mathrm{KCN}$. Upon literature review, $\mathrm{N}$-demethyl vandetanib, vandetanib $\mathrm{N}$-oxide and glucuronide conjugate were found in plasma, urine, and feces [1]. The full mechanism of bioactivation of vandetanib is not yet reported.

\section{Chemicals and methods Chemicals}

All chemicals are mentioned in Table 1. Rat liver microsomes (RLMs) were prepared in house according to previously published protocol [16-20].

\section{RLMs incubations}

Vandetanib $(20 \mu \mathrm{mol} / \mathrm{mL})$ was incubated at with RLMs $(1.0 \mathrm{mg} / \mathrm{mL}), \mathrm{NADPH}(1.0 \mathrm{mmol} / \mathrm{mL})$ and $\mathrm{K} / \mathrm{Na}$ phosphate buffer ( $50 \mathrm{mmol} / \mathrm{mL}$, pH 7.4) containing $\mathrm{MgCl}_{2}$ ( $3.3 \mathrm{mmol} /$ $\mathrm{mL}$ ). Incubation was done at thermostatted shaking water bath $\left(37^{\circ} \mathrm{C}\right)$ for $60 \mathrm{~min}$ before the reactions were quenched using two $\mathrm{mL}$ of $\mathrm{ACN}$ (ice-cold). The incubation mixtures were centrifuged at 14,000 rpm for $12 \mathrm{~min}$ then the supernatants were collected then subjected to dryness under a stream of $\mathrm{N}_{2}$. Samples residues were reconstituted in mobile

\section{Table 1 List of chemicals and materials}

\begin{tabular}{|c|c|}
\hline $\mathrm{Name}^{\mathrm{a}}$ & Source \\
\hline Dacomitinib & LC Laboratories (MA, USA) \\
\hline $\begin{array}{l}\text { Acetonitrile (ACN, HPLC-grade), } \\
\text { ammonium formate }\left(\mathrm{NH}_{4} \mathrm{COOH}\right) \text {, } \\
\text { poly ethylene glycol } 300(\mathrm{PEG} \\
\text { 300), dimethyl sulfoxide (DMSO), } \\
\text { potassium cyanide (KCN) and } \\
\text { formic acid (HCOOH) }\end{array}$ & Sigma-Aldrich (USA) \\
\hline Tween 80 & $\begin{array}{l}\text { Eurostar Scientific Ltd. (Liverpool, } \\
\text { UK) }\end{array}$ \\
\hline Water (HPLC grade) & $\begin{array}{l}\text { Milli-Q plus purification instrument } \\
\text { (USA) }\end{array}$ \\
\hline Sprague-Dawley rats ${ }^{\mathrm{b}}$ & $\begin{array}{l}\text { The experimental animal care center } \\
\text { at King Saud University (KSA) }\end{array}$ \\
\hline
\end{tabular}

phase (95\% solvent A and 5\% solvent B). The same steps were repeated using a trapping agent $(\mathrm{KCN}$ at $1.0 \mathrm{mmol} /$ $\mathrm{mL}$ ) to capture reactive intermediates forming adducts.

\section{In vivo metabolism of vandetanib}

Six male Sprague-Dawley rats of average weight (340 g) and 4 weeks of age were brought from animal house of King Saud University (Riyadh, KSA). Each rat was housed in special metabolism cage that was placed in animal care facility in a 12-h light/dark cycle (7:00-19:00). Rats had free access to standard water and animal food. Rats were maintained in metabolism cages for $72 \mathrm{~h}$ before study starting. Vandetanib was formulated in special solution (5\% Tween 80, 4\% DMSO, 30\% PEG 300, HPLC $\mathrm{H}_{2} \mathrm{O}$ ) to allow dispersion of vandetanib. Each rat received a calculated vandetanib depending on its weight.

The Recommended vandetanib dose is $300 \mathrm{mg}$ per day until unacceptable toxicity or disease progression occurs. Average vandetanib dose for human is $5 \mathrm{mg} / \mathrm{kg}$. Rat dose was calculated using these equations [21-23]:

$$
\begin{aligned}
& \text { Rat }(\mathrm{mg} / \mathrm{kg})=\text { Human }(\mathrm{mg} / \mathrm{kg}) * \text { Human } \mathrm{Km} / \text { Rat } \mathrm{Km} \\
& \text { Rat }(\mathrm{mg} / \mathrm{kg})=5 * 37 / 6 \\
& \text { Rat }(\mathrm{mg} / \mathrm{kg})=185 / 6 \\
& \text { Rat }(\mathrm{mg} / \mathrm{kg})=30.8(\mathrm{mg} / \mathrm{kg})
\end{aligned}
$$

So the dose for rat was $30.8 \mathrm{mg} / \mathrm{kg}$. Rats were given a single calculated dose of vandetanib. One rat was used as a control and was given solvent without vandetanib. Oral gavage was used for vandetanib dosing to rats. Urine samples were collected after draining into compartments fixed to metabolism cages before vandetanib dosing as 
control sample and at specific time periods $(6,12,18,24$, $48,72,96$ and $120 \mathrm{~h}$ ) following vandetanib dosing. Filtration of Urine samples was done using $0.45 \mu \mathrm{m}$ syringe filters for discarding of particulate matters in the urine. A similar volume of ACN was added to each collected urine sample and then the resulted mixture was shaken by vortexing for $1 \mathrm{~min}$. After storing the mixture at $4{ }^{\circ} \mathrm{C}$ overnight, two solvent layers (upper organic layer and lower aqueous layer) were formed. Both layers were evaporated until dryness under stream of $\mathrm{N}_{2}$ and reconstituted respectively in $1 \mathrm{~mL}$ of mobile phase and transferred to HPLC Agilent vials for LC-MS/MS analysis. Control urine samples obtained from rats before drug dosing were done in the same way described for sample purification method. These samples were analyzed by LC-MS/ MS to obtain control chromatograms.

\section{Chromatographic conditions}

The adjusted liquid and mass chromatographic conditions for the separation and identification of in vitro and in vivo vandetanib metabolites are described in details in Table 2.

\section{Identification of in vitro metabolites, in vivo metabolites and cyano conjugates of vandetanib}

Extracted ion chromatograms (EICs) for the vandetanib proposed metabolites were used to identify metabolites in the total ion chromatogram (TIC) of ether RLMs incubation extract or urine extract. CID of proposed metabolites molecular ion peaks (MIP) of was performed in the collision cell to get product ion (PI) mass spectra.
Structures of metabolites were done by reconstructing the product ions. In vivo vandetanib-related metabolites were concentrated in the organic layer while endogenous components of the urine and highly polar metabolites were located in the aqueous layer.

\section{Results and discussion}

Identification of in vitro phase 1 vandetanib metabolites Six phase 1 metabolites were identified: one demethylated $(m / z-14)$ which was identified as VA461, two metabolites with one $N$-oxide or mono hydroxyl $(m / z+16)$ which were identified as VA491a and VA491b, one metabolite with oxidation of $\alpha$-carbon and $N$-demethylation of $N$-piperidine which was identified as VA475 and two metabolites at $\mathrm{m} / \mathrm{z} 489$ which was identified as VA489a and VA489b (Table 3). Six metabolites were formed by incubation of vandetanib with RLMs through four metabolic reactions: $N$-demethylation, $N$-oxide formation, $\alpha$-carbonyl formation, and $\alpha$-hydroxylation (Table 3).

\section{Identification of vandetanib and VA475 metabolite}

Vandetanib and VA475 metabolite MIPs were detected at $m / z 475$ in full MS scan mode at retention times $\left(t_{R}\right)$ of 50.3 and $54.7 \mathrm{~min}$, respectively (Fig. 1a). Upon CID of MIPs at $m / z 475$ gave different daughter ions (Fig. 1b). Collision induced dissociation (CID) of vandetanib inside collision cell of triple quadruploe at $\mathrm{m} / z 475$ provided one daughter at $m / z 112$ (Fig. 1b). Daughter at $m / z 112$ represents methyl $N$-methyl piperidine moiety (Scheme 1).

Table 2 Optimized parameters of the established LC-MS/MS methodology

\begin{tabular}{|c|c|c|c|c|c|c|}
\hline \multicolumn{4}{|l|}{ LC parameters } & \multicolumn{3}{|l|}{ MS/MS parameters } \\
\hline HPLC & \multicolumn{3}{|c|}{ Agilent 1200 (Agilent Technologies, CA, USA) } & Mass spectrometer & \multicolumn{2}{|c|}{$\begin{array}{l}\text { Agilent } 6410 \text { QqQ (Agilent Technologies, CA, } \\
\text { USA) }\end{array}$} \\
\hline \multirow[t]{4}{*}{$\begin{array}{l}\text { Mobile phase (gradi- } \\
\text { ent) }\end{array}$} & \multicolumn{3}{|c|}{$\begin{array}{l}\text { Aqueous phase: } 10 \mathrm{mM} \text { Ammonium formate in } \mathrm{H}_{2} \mathrm{O}(\mathrm{pH}: 4.1 \\
\text { using Formic acid) }\end{array}$} & Ionization source & \multicolumn{2}{|c|}{ Positive electrospray ionization (ESI) } \\
\hline & \multicolumn{3}{|c|}{ Organic phase: ACN (0.1\% Formic acid) } & & \multirow{2}{*}{\multicolumn{2}{|c|}{$\begin{array}{l}\text { Drying gas: } \mathrm{N}_{2} \text { gas } \\
\text { Pressure }(55 \mathrm{psi})\end{array}$}} \\
\hline & \multicolumn{3}{|l|}{ Flow rate: $0.2 \mathrm{~mL} / \mathrm{min}$} & & & \\
\hline & Elution time: $90 \mathrm{~min}$ & & & & \multicolumn{2}{|l|}{ Flow rate $(12 \mathrm{~L} / \mathrm{min})$} \\
\hline \multirow{5}{*}{$\begin{array}{l}\text { Agilent eclipse plus } \mathrm{C}_{18} \\
\text { Column }\end{array}$} & & In vitro & In vivo & & \multicolumn{2}{|l|}{ ESI temperature: $350^{\circ} \mathrm{C}$} \\
\hline & Length (mm) & 50 & 150 & & \multicolumn{2}{|l|}{ Capillary voltage: $4000 \mathrm{~V}$} \\
\hline & Internal diameter (mm) & 2.1 & 2.1 & Collision gas & \multicolumn{2}{|l|}{$\mathrm{N}_{2}$ (high purity) } \\
\hline & Particle size $(\mu \mathrm{m})$ & 1.8 & 3.5 & Modes & \multicolumn{2}{|c|}{ Product ion (PI) and full mass scan and } \\
\hline & Temperature: & \multicolumn{2}{|c|}{$22 \pm 2^{\circ} \mathrm{C}$} & Software & \multicolumn{2}{|l|}{ Mass Hunter software } \\
\hline \multirow[t]{6}{*}{ Elution system } & Time (min) & \multicolumn{2}{|c|}{$\% \mathrm{~B}(\mathrm{ACN})$} & Analyte & \multirow{2}{*}{\multicolumn{2}{|c|}{$\begin{array}{l}\text { Vandetanib, in vivo, in vitro and reactive } \\
\text { metabolites }\end{array}$}} \\
\hline & 0 & \multicolumn{2}{|l|}{5} & & & \\
\hline & 60 & \multicolumn{2}{|l|}{25} & Mass conditions & \multirow[t]{3}{*}{ Fragmentor voltage $(\mathrm{V})$} & \multirow[t]{3}{*}{140} \\
\hline & 80 & \multicolumn{2}{|l|}{70} & & & \\
\hline & 90 & \multicolumn{2}{|l|}{5} & & & \\
\hline & Post time 15 & \multicolumn{2}{|l|}{5} & & Collision energy (eV) & 15 \\
\hline
\end{tabular}


Table 3 Phase I metabolites of Vandetanib using MS scan and PI scan

\begin{tabular}{llllll}
\hline & MS scan & $\begin{array}{l}\text { Major } \\
\text { daughter ions }\end{array}$ & $\mathbf{t}_{\mathbf{R}}$ (min) & Metabolic pathway & \multicolumn{1}{c}{$\begin{array}{l}\text { Proposed conjugate } \\
\text { composition } \\
\text { Previously } \\
\text { detected } \\
\text { (reference) }\end{array}$} \\
\hline VNT & 475 & 112 & 50.4 & & $\mathrm{~V}+\mathrm{H}$ \\
VA461 & 461 & 364,98 & 49.7 & $\mathrm{~N}$-demethylation & $\mathrm{V}-\mathrm{CH}_{2}+\mathrm{H}$ \\
VA475 & 475 & 112,110 & 54.7 & $\mathrm{~N}$-demethylation and a oxidation & $\mathrm{V}-\mathrm{CH}_{2}+\mathrm{O}+\mathrm{H}$ \\
VA489a & 489 & 126 & 66.8 & a oxidation & $\mathrm{V}+\mathrm{O}-2 \mathrm{H}+\mathrm{H}$ \\
VA489b & 489 & 364 & 67.9 & $\mathrm{~N}$-demethylation and 2 a oxidation & $\mathrm{V}-\mathrm{CH}_{2}+2 \mathrm{O}+\mathrm{H}$ \\
VA491a & 491 & 128,111 & 57.1 & a Hydroxylation & $\mathrm{V}+\mathrm{O}+\mathrm{H}$ \\
VA491b & 491 & 189,128 & 50.4 & $\mathrm{~N}$-oxidation & $\mathrm{V}+\mathrm{O}+\mathrm{H}$ \\
\hline
\end{tabular}

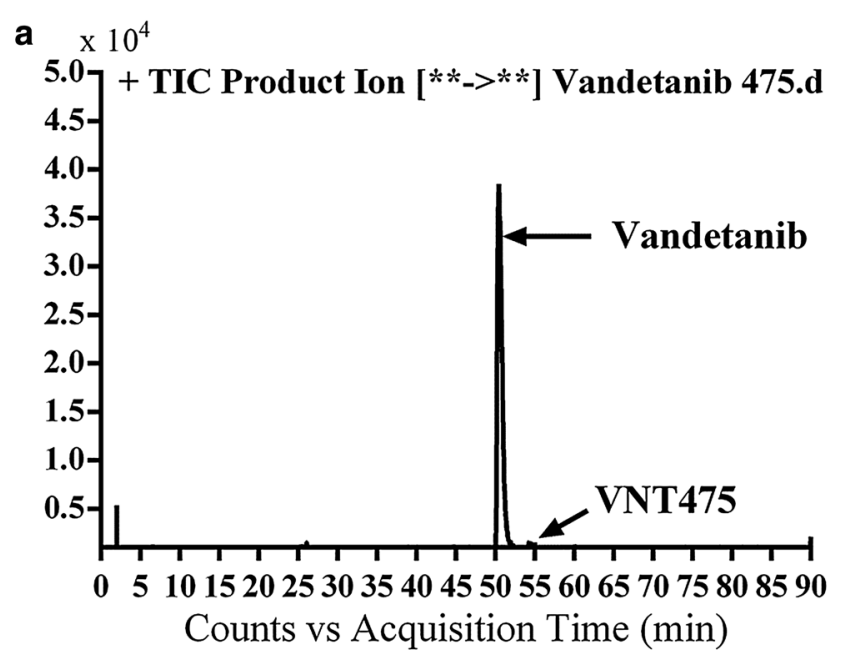

b

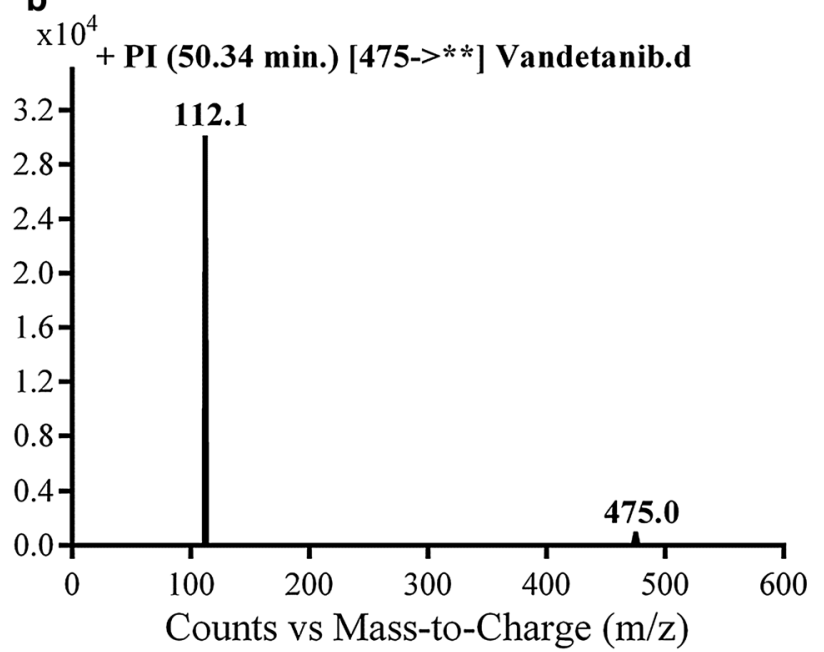

C

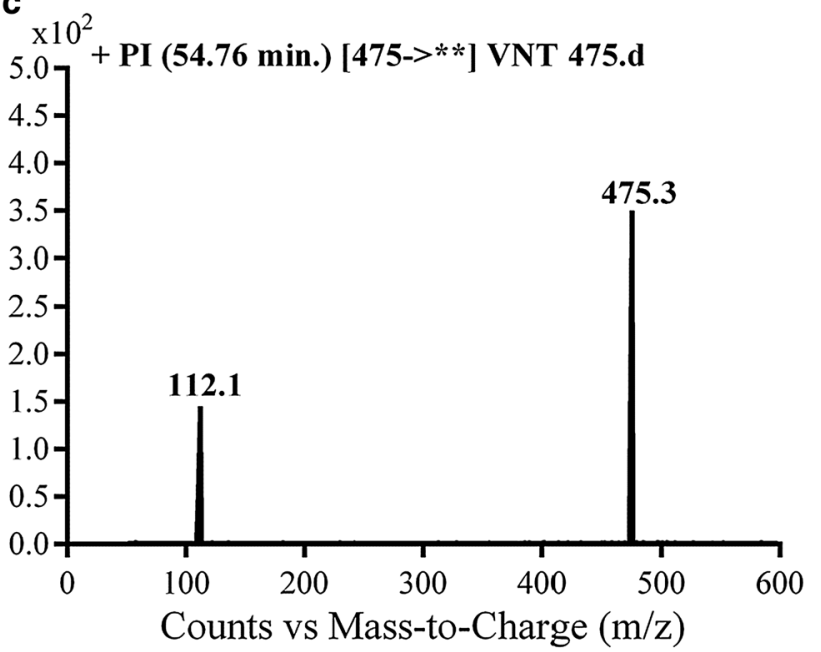

Fig. 1 EIC of MIP at m/z 475 showing two peaks; vandetanib (50.3 min) and VA475 (54.8 min) (a), PI mass spectrum of vandetanib (b) and PI mass spectrum of VA475 at $\mathrm{m} / \mathrm{z} 475$ (c)

CID of VA475 MIP at $m / z 475$ gave daughters at $m / z$ 112 and 110 in PI scan by QqQ MS (Fig. 1c). The fragment ion at $m / z 112$ proposed the removal of the methyl group from the $N$-methyl piperidine and oxidation of $\alpha$-carbon in the ring which matched with the other daughter ion at $m / z$ of 110 (Scheme 2). 


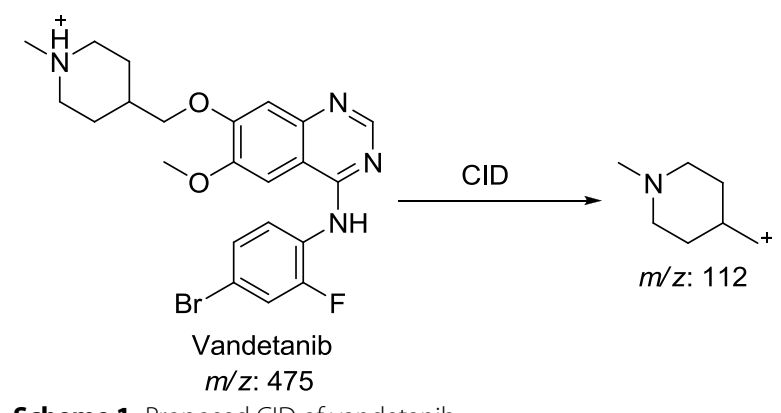

Scheme 1 Proposed CID of vandetanib

\section{Identification of VA461 metabolite}

VA461 metabolite of Vandetanib was detected at $m / z 461$ in full scan mode at $t_{\mathrm{R}}$ of $49.7 \mathrm{~min}$ (Fig. 2a). CID of MIP at $m / z 461$ generates fragment ion at $m / z 98$ (Fig. 2b). The daughter ion at $m / z 98$ supposed that the metabolic pathway is $N$-demethylation of the methyl group from the methyl piperidine ring, which matched with the other fragment ions at $m / z$ 364. VA461 metabolite was the net product of removal of methyl group from $N$-methyl piperidine group in vandetanib (Scheme 3).

\section{Identification of VA489 metabolite}

VA489a and VA489b metabolites of vandetanib were detected at $m / z 489$ in MS scan mode at $t_{\mathrm{R}}$ of 66.8 and 67.9 min, respectively (Fig. 3a). CID of MIPs at $m / z 489$ gave various daughter ions (Fig. $3 \mathrm{~b}, \mathrm{c}$ ).

In case of VA489a, the fragment ion at $m / z 126$ supposed that the metabolic reactions were $\alpha$-carbonyl formation of $N$-methyl piperidine group (Scheme 4).

In case of VA489a, the fragment ion at $m / z 364$ supposed that metabolic reactions were $2 \alpha$-carbonyl formation and $N$-demethylation at $N$-methyl piperidine ring (Scheme 5).
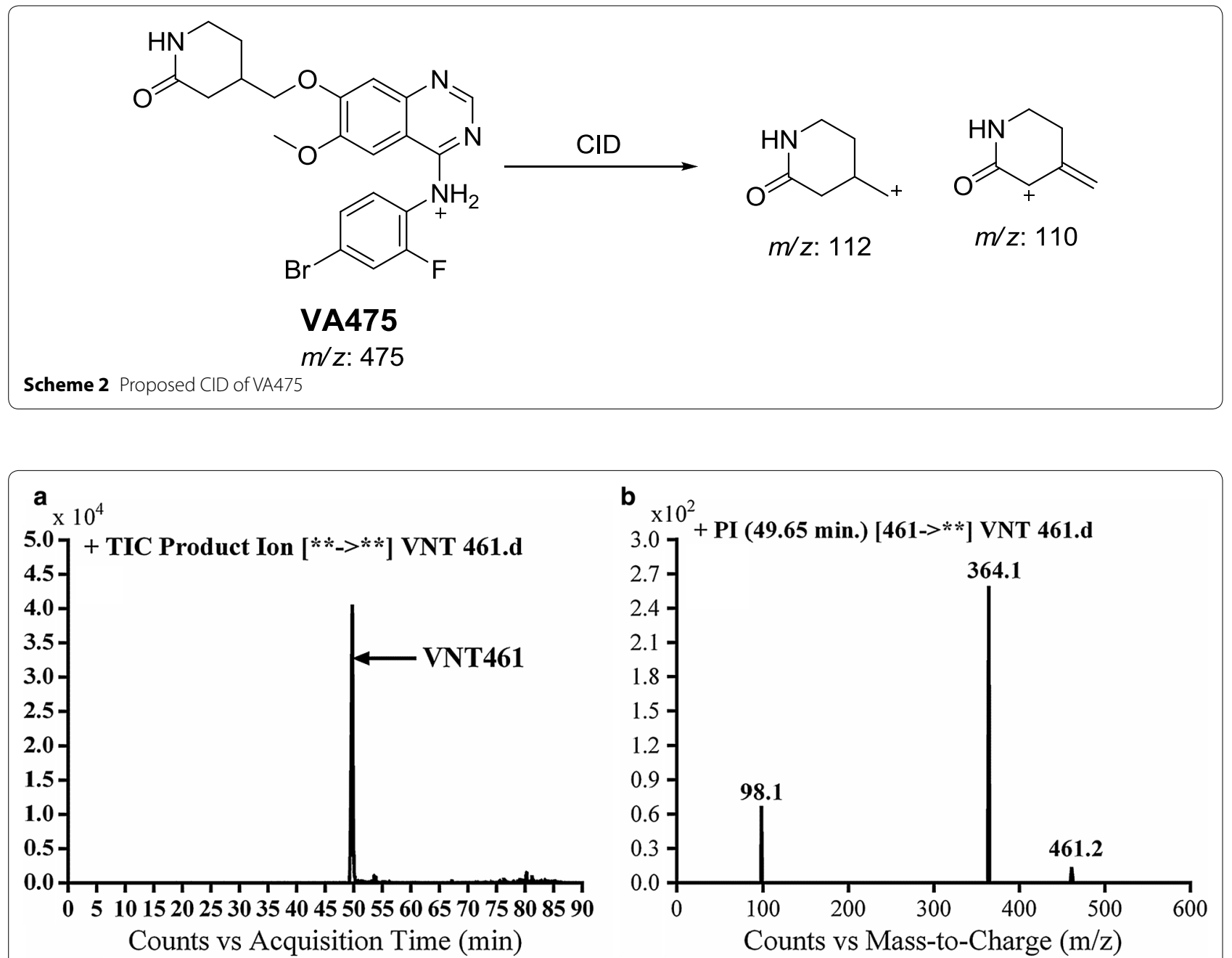

Fig. 2 EIC of MIP at m/z 461 showing one peak (VA461) at $49.7 \mathrm{~min}$ (a) and PI mass spectrum of VA461 at $\mathrm{m} / \mathrm{z} 461$ (b) 


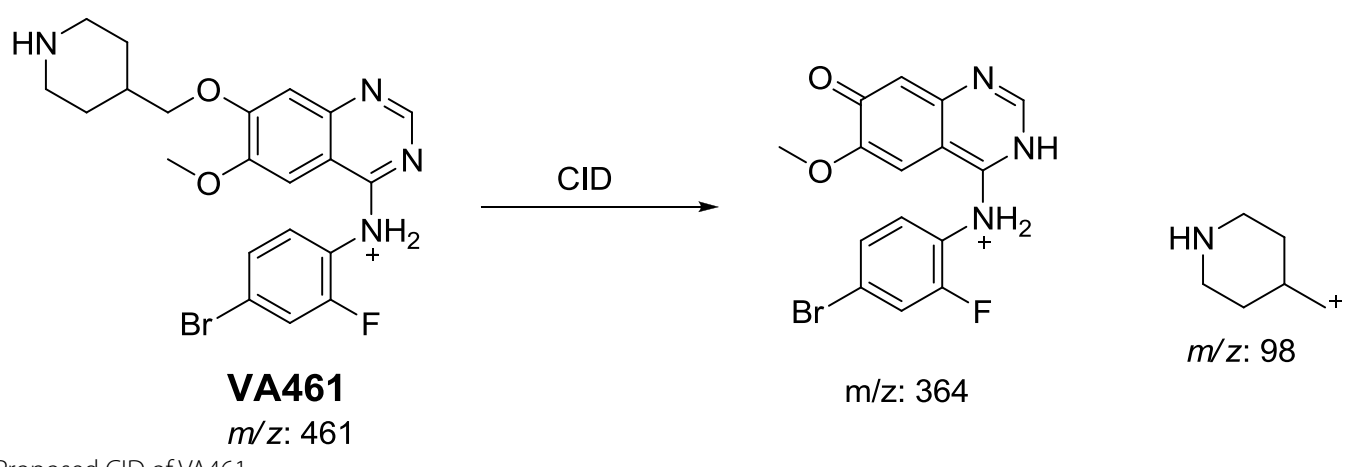

Scheme 3 Proposed CID of VA461
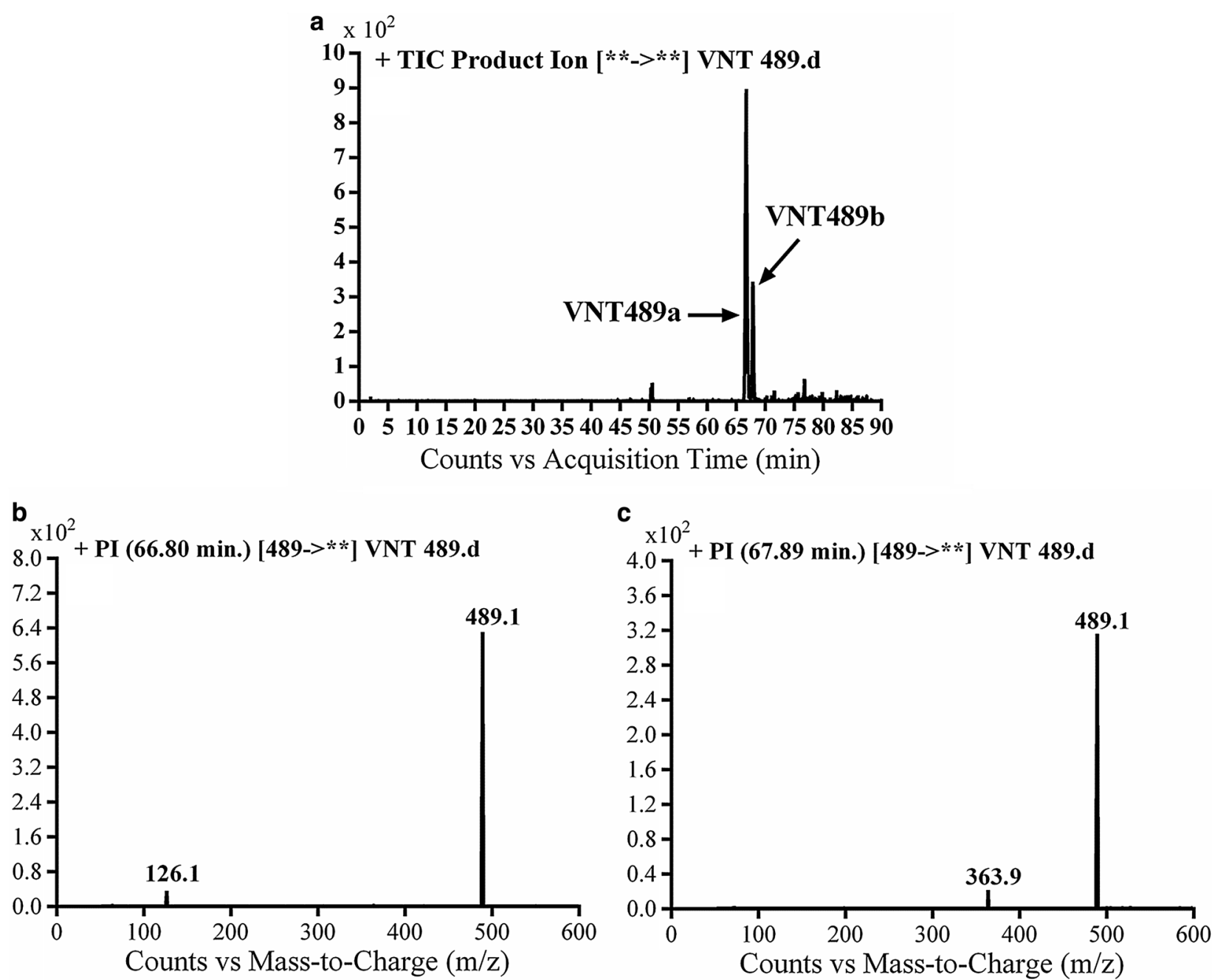

Fig. 3 ElC of MIP at m/z 489 showing two peaks: VA489a (66.8 min) and VA489b (67.9 min) (a), PI mass spectra of VA489a (b) and VA489b at m/z 489 (c) 


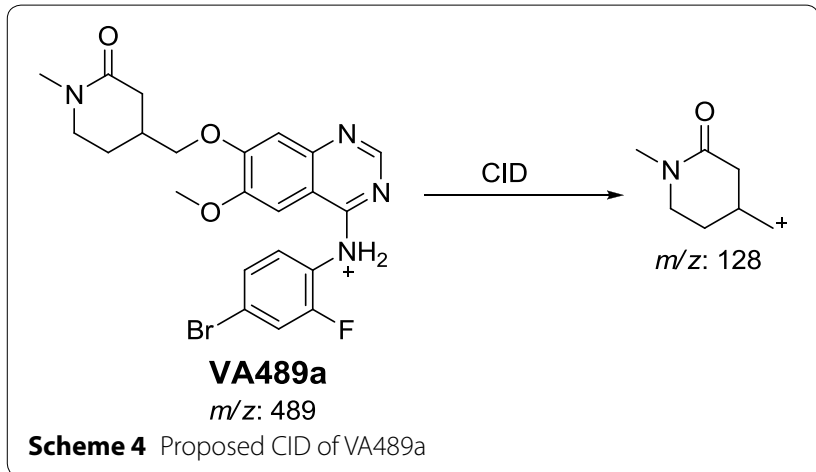

\section{Identification of VA91 $a$ and VA491b metabolite}

VA491a and VA491b metabolites of vandetanib were detected at $m / z 491$ in MS scan mode at $\mathrm{t}_{\mathrm{R}}$ of 57.1 and $67.4 \mathrm{~min}$, respectively (Fig. 4a). CID of MIPs at $\mathrm{m} / z 491$ gave different daughter ions (Fig. 4b, c).

In the case of VA491a, the fragment ion at $\mathrm{m} / z 128$ supposed that metabolic reaction was hydroxylation of $\alpha$-carbon of $N$-methyl piperidine ring which matched with the daughter ion at $m / z 111$ (Scheme 6).

In case of VA491b, the fragment ion at $\mathrm{m} / z 128$ proposed that $N$-oxide formation metabolic reaction occurred at $N$-methyl piperidine ring (Scheme 7).

\section{Characterization of vandetanib reactive metabolites}

Extracts of vandetanib in vitro incubations in the presence of $1.0 \mathrm{mM} \mathrm{KCN}$ with RLMs were injected into LCQqQ. Identification of MIPs representing vandetanib cyanide conjugates was performed with mass scan and
PI scan for these peaks (Table 4). Four cyanide conjugates were identified, indicating that the $N$-methyl piperidine ring in vandetanib can become bioactivated and then captured by the nucleophile cyanide ion [19].

\section{Identification of VB486 cyano conjugate of vandetanib}

VB486 cyano conjugate was detected at $m / z 486$ in MS scan mode with $t_{\mathrm{R}}$ of $71.7 \mathrm{~min}$. CID of MIP at $\mathrm{m} / z 486$ generates fragment ions at $m / z 363$ and 389 (Fig. 5). The fragment ion at $m / z 389$ proposed cyano group addition to the bio activated $\alpha$-carbon and $N$-demethylation of piperidine ring. The metabolic pathway in VB486 revealed to $\alpha$-cyano $N$-demethyl vandetanib (Scheme 8).

\section{Identification of VB500a and VB500b cyano conjugates of vandetanib}

VB500a and VB500b cyano conjugates of vandetanib were detected at $m / z 500$ in MS scan mode with $t_{R}$ of 68.4 and $76 \mathrm{~min}$, respectively (Fig. 6a). CID of MIP at $\mathrm{m} / \mathrm{z}$ 500 gave various fragment ions (Fig. 6b, c).

In case of VB500a, the fragment ion at $\mathrm{m} / z 137$ proposed that cyano group addition occurred at activated $\alpha$ carbon of the methyl piperidine ring. The other fragment ion at $m / z 473$ represented the cyano group loss (Scheme 9). The metabolic pathway in VB500a revealed to $\alpha$ cyano vandetanib.

In case of VB500b, fragment ions at $\mathrm{m} / z 164$ and $\mathrm{m} / z$ 457 proposed that $\alpha$-carbonyl formation, $N$-demethylation and cyano group addition to the activated $\alpha$ carbon (Scheme 10). The metabolic reaction in VB500b revealed to $\alpha$-cyano $\alpha$-Keto $N$-demethyl vandetanib.<smiles>COc1cc2c([NH3+])ncnc2cc1OCC1CC(=O)NC(=O)C1</smiles>

VA489b

$m / z: 489$<smiles>COc1cc2c(N)[nH]cnc-2cc1=O</smiles>

$m / z: 364$

Scheme 5 Proposed CID of VA489b 


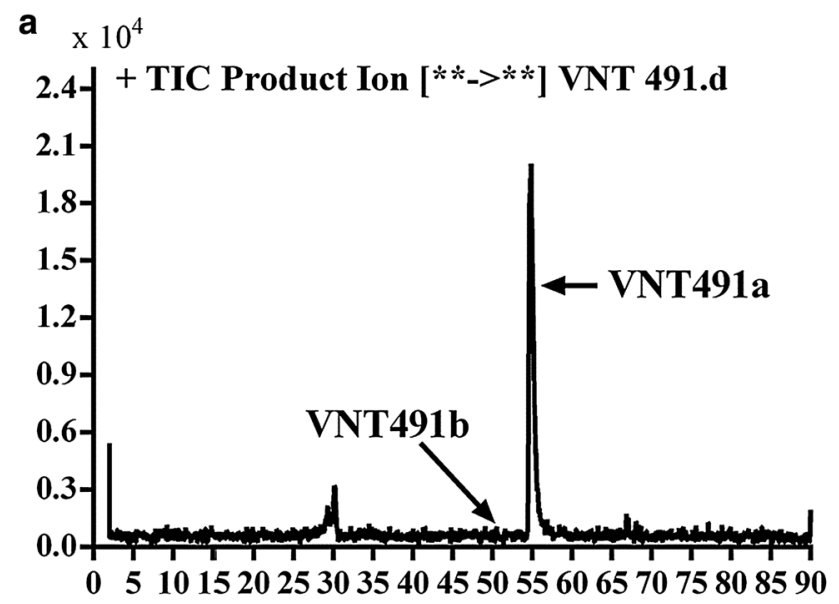

Counts vs Acquisition Time (min)
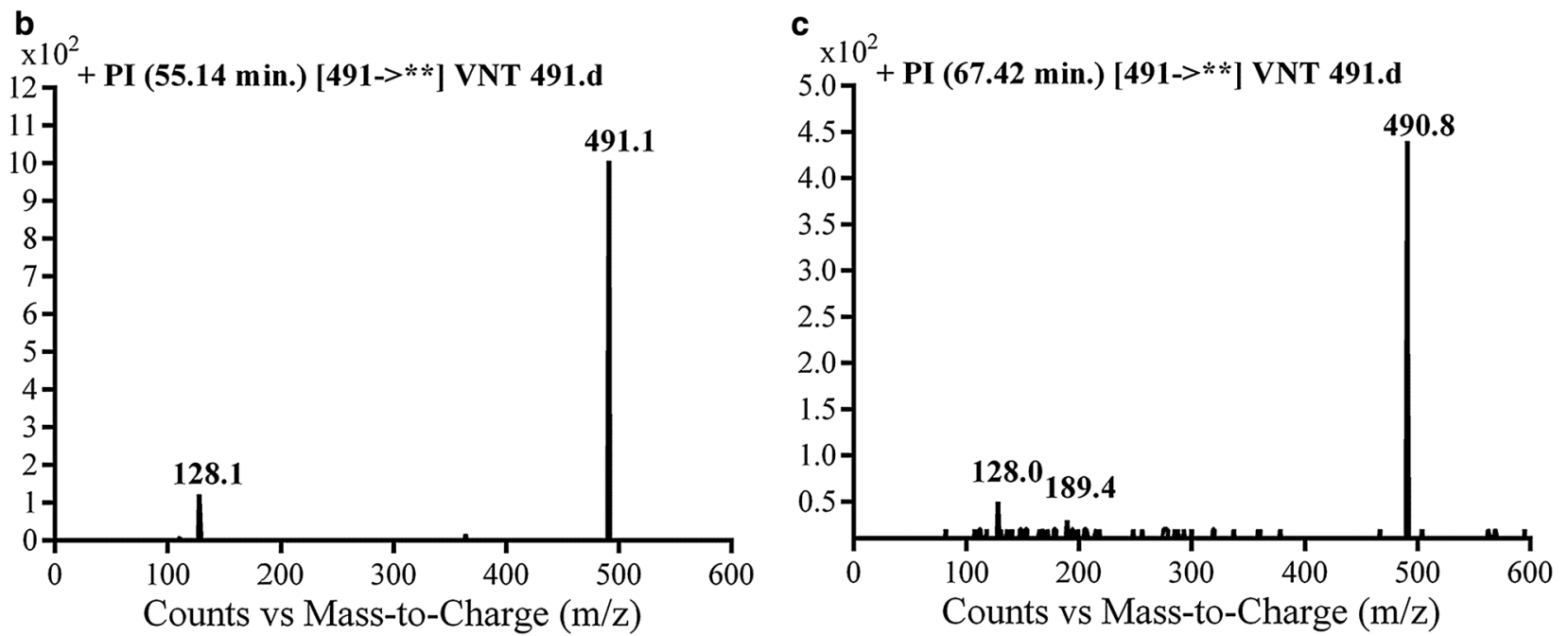

Fig. 4 PI chromatogram of MIP at m/z 491 showing two peaks: VA491a (57.1 min) and VA491b (67.4 min) (a), PI mass spectra of VA491a (b) and VA491 b at $m / z 491$ (c)

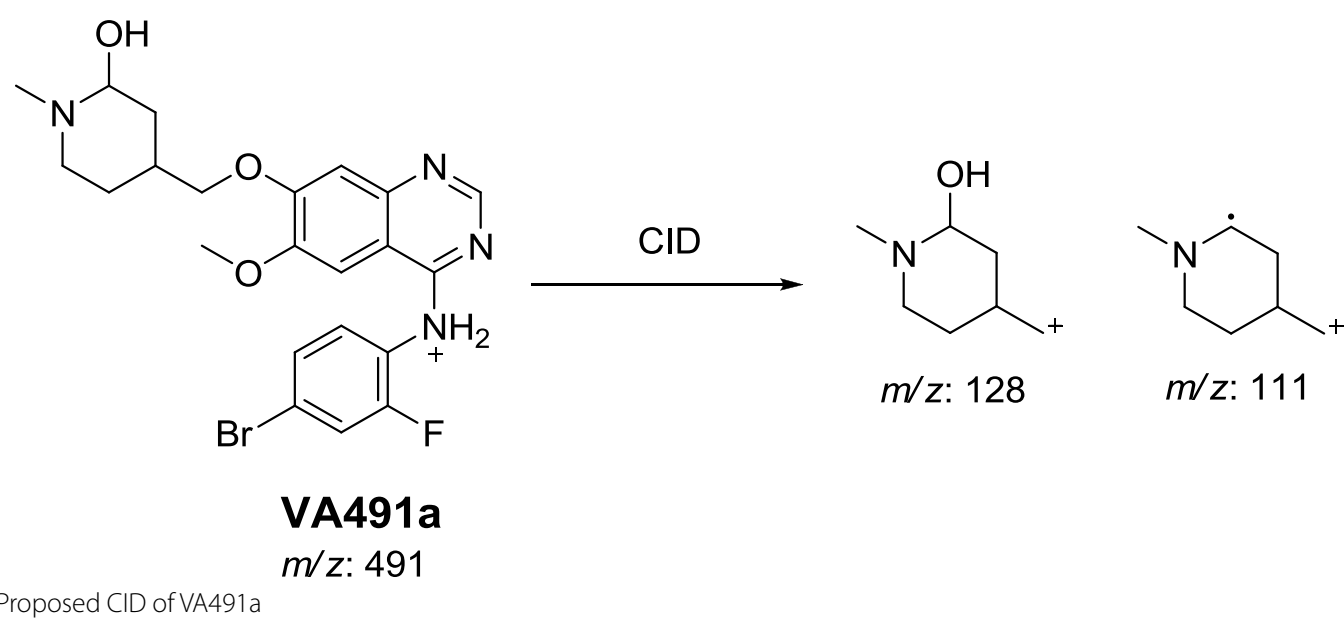


<smiles></smiles>

VA491b

$m / z: 491$

Scheme 7 Proposed CID of VA491b

Table 4 Vandetanib cyano conjugates

\begin{tabular}{|c|c|c|c|c|c|}
\hline Code & MS scan & Major fragments & $t_{R}(\min )$ & Metabolic pathway & $\begin{array}{l}\text { Postulated } \\
\text { conjugate } \\
\text { composition }\end{array}$ \\
\hline VB486 & 486 & $389.4,363.2$ & 71.6 & a Cyano addition and $\mathrm{N}$-demethylation & $\mathrm{V}-\mathrm{CH}_{3}+\mathrm{CN}$ \\
\hline VB500a & $500 a$ & $373.2,137.1$ & 68.4 & a Cyano addition & $\mathrm{V}+\mathrm{CN}$ \\
\hline VB500b & $500 b$ & $456.9,163.9$ & 76 & N-demethylation, a oxidation and a Cyano addition & $\mathrm{V}-\mathrm{CH}_{3}+\mathrm{CN}+\mathrm{O}$ \\
\hline VB502 & 502 & $484.3,361.3,287.4,203.1$ & 77.1 & N-demethylation, a hydroxylation and a Cyano addition & $\mathrm{V}-\mathrm{CH}_{3}+\mathrm{CN}+\mathrm{OH}$ \\
\hline
\end{tabular}

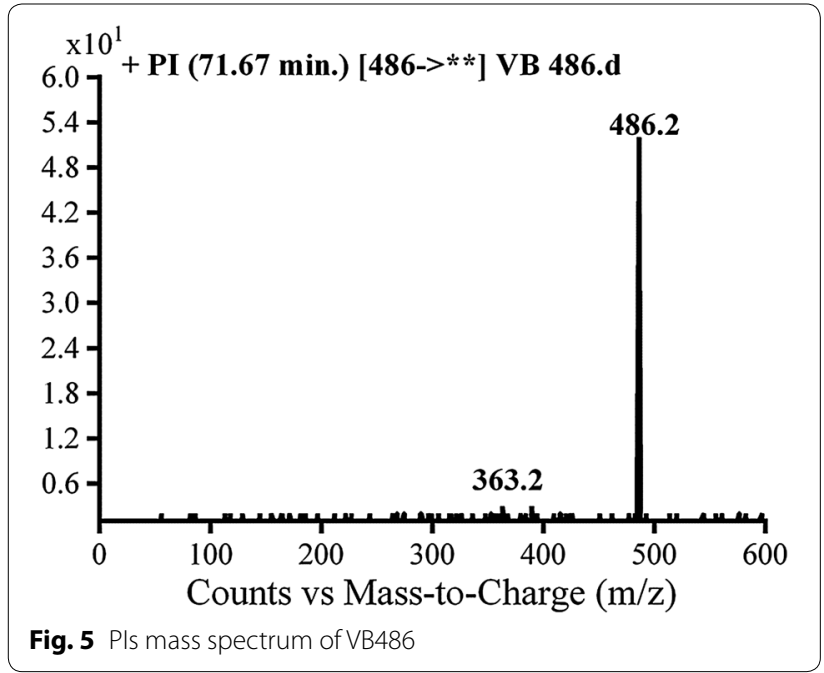

\section{Identification of VB502 cyano conjugate of vandetanib}

VB502 cyano adduct of vandetanib was detected at $\mathrm{m} / \mathrm{z}$ 502 in MS scan mode at $t_{\mathrm{R}}$ of $77.1 \mathrm{~min}$ (Fig. 7a). CID of MIP at $m / z 502$ generates fragment ions at $m / z 203, m / z$ 287, $m / z 362$ and $m / z 484$ (Fig. 7b). Daughter ion at $m / z$ 362 supposed that all metabolic reactions happened in the piperidine group. Fragment ions at $m / z 484$ and $m / z$ 362 proposed that hydroxylation of $\alpha$ carbon, $N$-demethylation of piperidine group and cyano group addition to the activated $\alpha$-carbon piperidine ring (Scheme 11). The metabolic reaction in VB500b revealed to $\alpha$-cyano $\alpha$-hydroxyl vandetanib.

\section{Bioactivation mechanism of vandetanib}

Vandetanib contains cyclic tertiary amine group, $N$-methyl piperidine, that is able to form iminium intermediates which are reactive and can be captured 

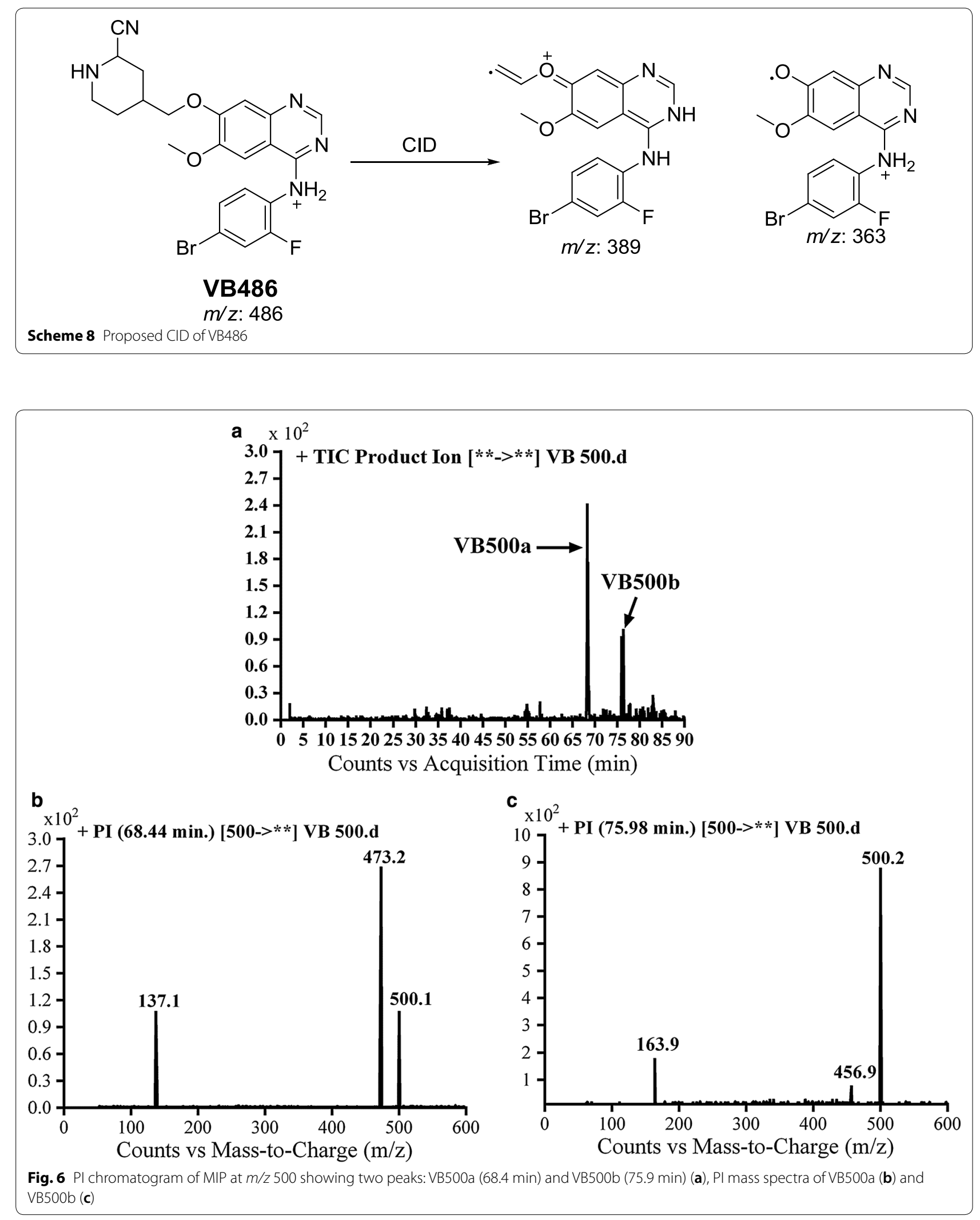

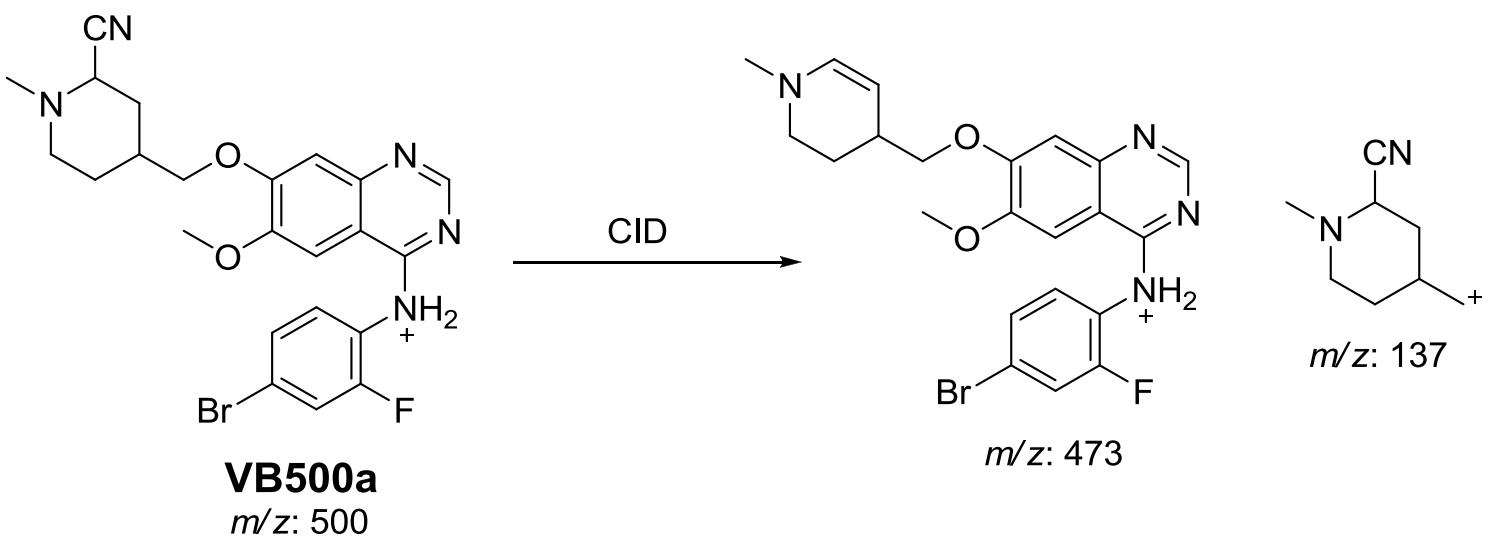

$m$ z: 137

Scheme 9 Proposed CID of VB500a
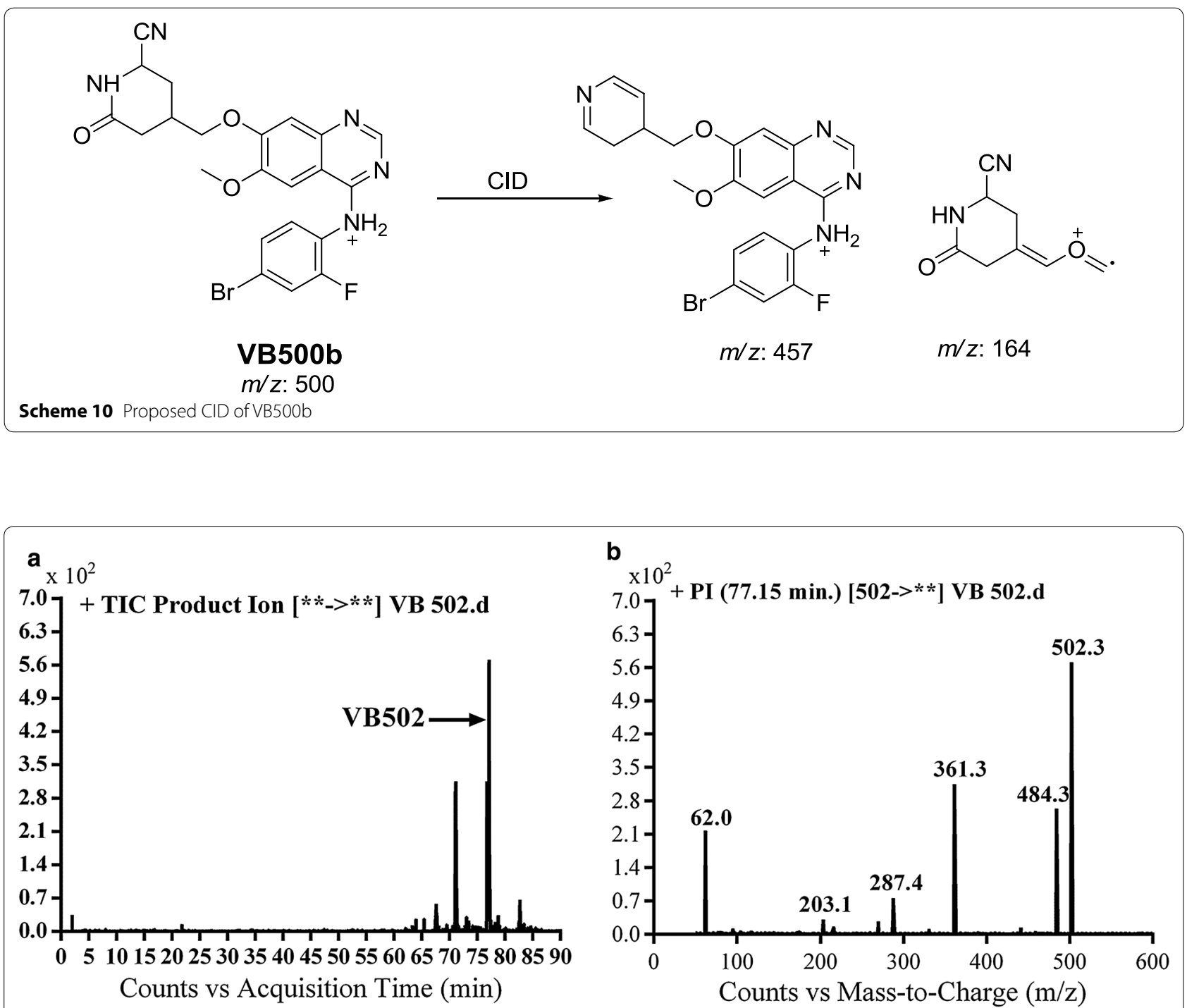

Fig. 7 PI chromatogram of MIP at $m / z 502$ showing one peak (VB502) at $77.1 \mathrm{~min}$ (a), PI mass spectrum of VB502 (b) 
<smiles>COc1cc2c(Nc3ccc(Br)cc3F)ncnc2cc1OCC1CC(O)NC(C#N)C1</smiles><smiles>COc1cc2c(N[C@H](C)CC3C=CNC(C#N)C3)ncnc2cc1OCC1CCC(C)(C)C1</smiles><smiles></smiles>

Scheme 11 Proposed CID of VB502

using $\mathrm{KCN}$. The chemical structures of four cyanide conjugates of vandetanib were recognized and bioactivation reactions of the $N$-methyl piperidine ring were explained as shown in Scheme 12. The $N$-methyl piperidine ring in vandetanib underwent P450-catalyzed oxidation and or hydroxylation and subsequent dehydration forming imine and imine-carbonyl intermediates ( $\alpha, \beta$-unsaturated) which was trapped by $\mathrm{KCN}$ to form stable conjugate that was characterized and detected in the tandem mass spectrometry detector $[19,20,24,25]$.

\section{Identification of vandetanib in vivo metabolites}

PI mass spectra comparison between control urine samples with urine extracts as well as PI comparison of vandetanib and proposed metabolites (Table 3) permitted the identification of four in vivo phase I and one phase II metabolites. Metabolic reactions for in vivo phase I metabolites were proposed to be $N$-oxide formation, $N$-demethylation and $\alpha$-hydroxylation while for phase II metabolites were the result of $\mathrm{N}$-conjugation of vandetanib with glucuronic acid. In vivo vandetanib phase I metabolites are previously mentioned in in vitro vandetanib phase I metabolism.

\section{Excretion of vandetanib and its in vivo metabolites in rat urine}

Part of vandetanib oral dose was excreted unchanged in rat urine. Vandetanib was detected at $\mathrm{m} / z 475$ in
MS scan spectrum. Excretion of vandetanib and its in vivo phase I metabolites in urine were noticed after $6 \mathrm{~h}$ of dosing. Comparative concentration of vandetanib was high after $6 \mathrm{~h}$ and began to increase by time and reach maximum at $24 \mathrm{~h}$ and begin to decrease until almost disappeared after $120 \mathrm{~h}$ from dosing as indicated in the overlayed PI chromatograms for vandetanib and its in vivo phase I metabolites (Fig. 8). Comparison of vandetanib PIs with proposed peaks permitted the identification of metabolic changes in the found in vivo metabolites. All in vivo metabolites are similar to in vitro metabolites and the disappearance of $\alpha$ oxidation metabolic reaction in the in vivo metabolism.

\section{Phase II vandetanib in vivo metabolites: glucuronic acid conjugates}

In vivo phase II metabolic reaction was direct conjugation of vandetanib with glucuronic acid. VC651 was located in the aqueous layer in a very small concentration in comparison to in vivo phase I metabolites. Excretion of in vivo phase II metabolites in urine was noticed after $24 \mathrm{~h}$ of rat dosing and vanished rapidly after $48 \mathrm{~h}$ of rat dosing. VC651 was detected at $m / z 651$ in MS scan spectrum of the aqueous layer urine extract. PI scan for VC651 at $31.7 \mathrm{~min}$ gave fragment ions at $m / z 112$ (Fig. 9). VC651 was proposed to be the result of was direct conjugation of glucuronic acid with vandetanib (Scheme 13). 


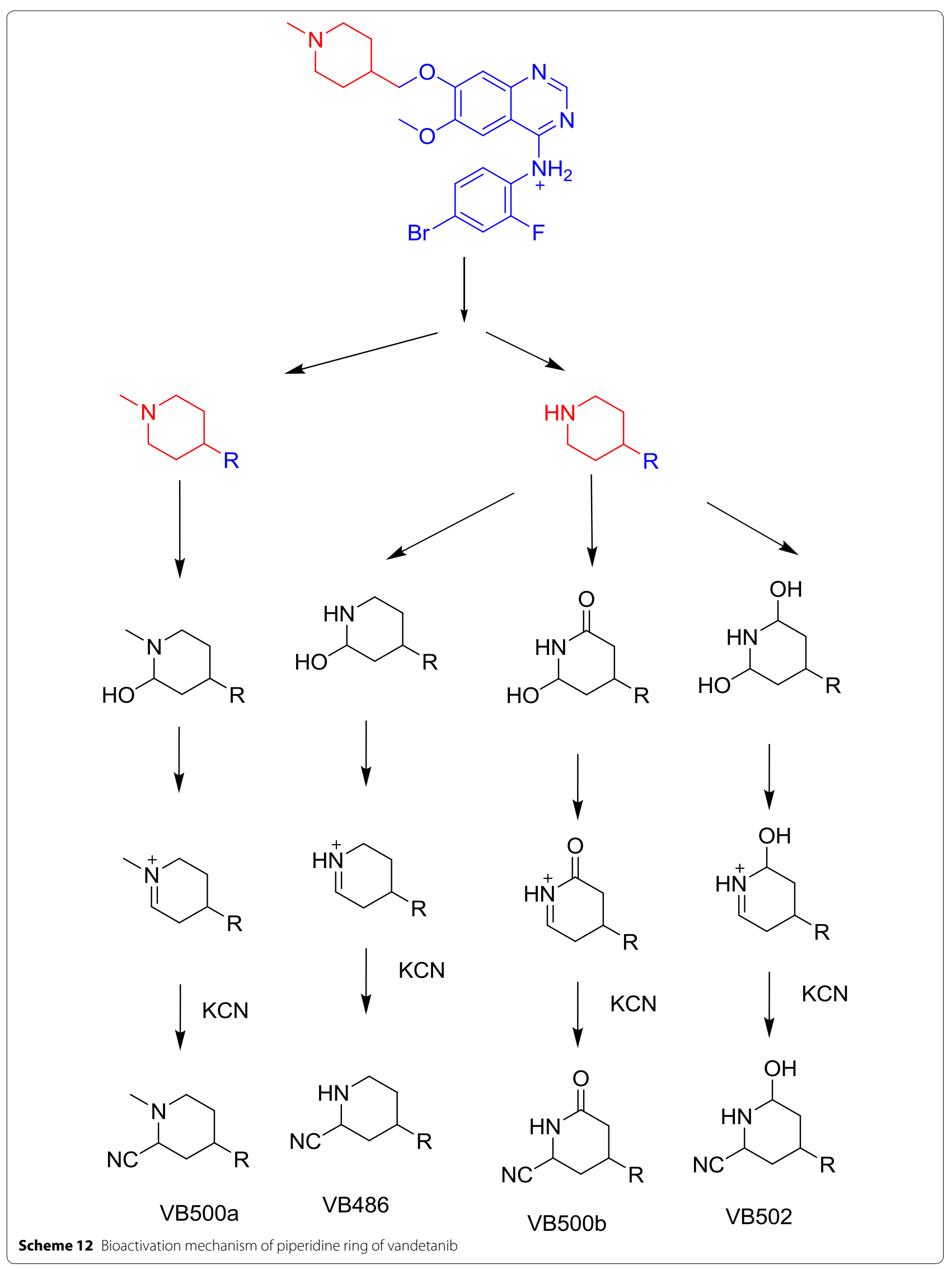




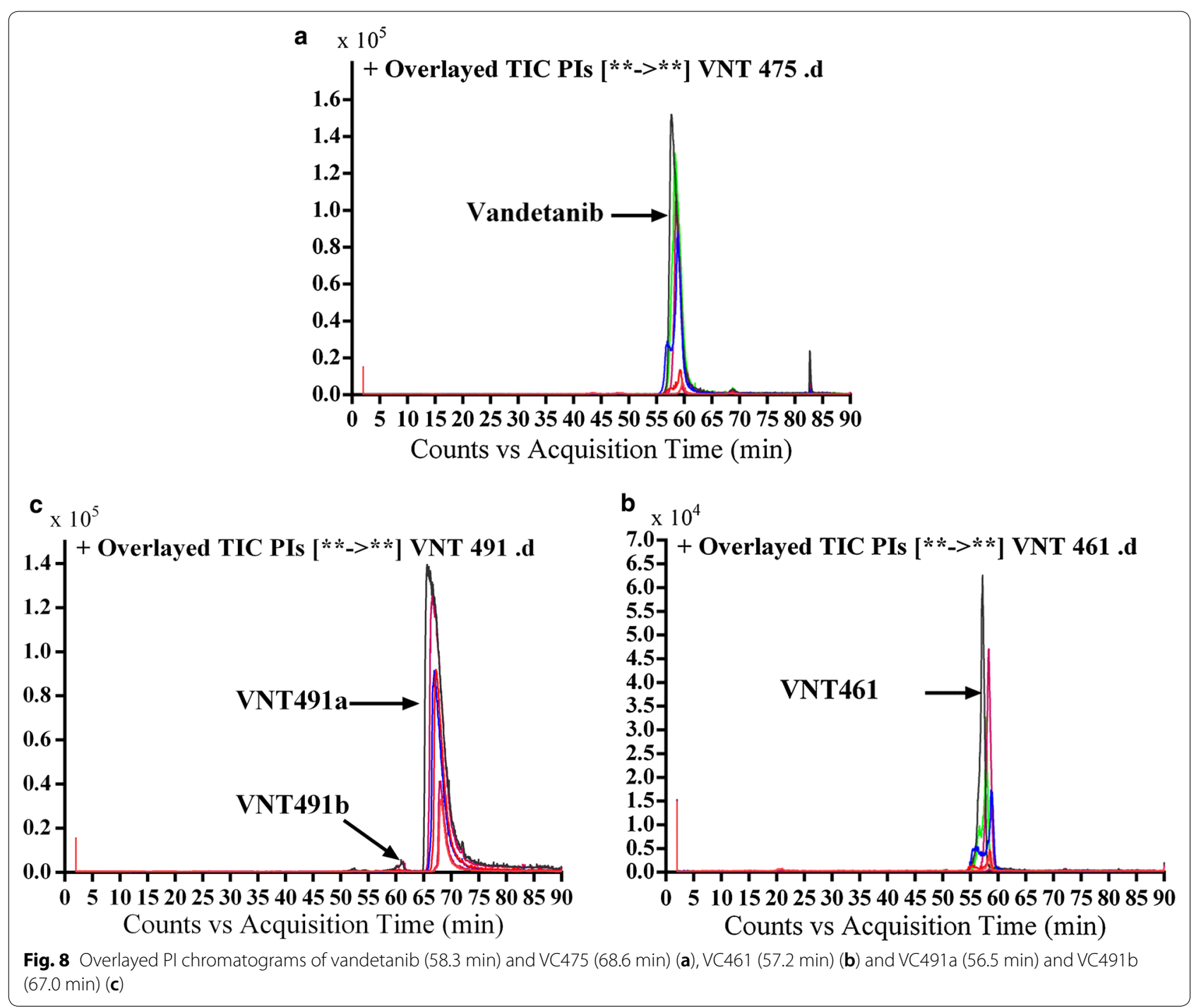

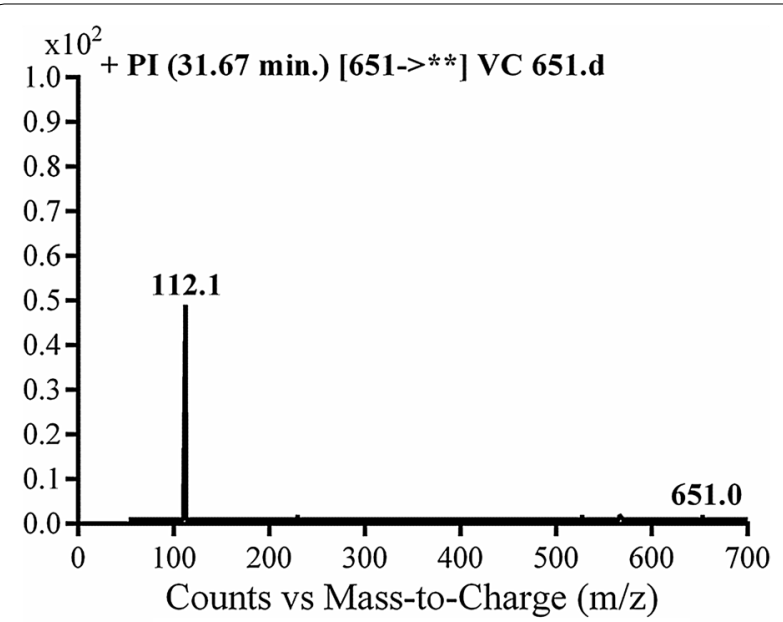

Fig. 9 PI mass spectrum of VC651

\section{Conclusions}

Four in vivo phase I, one in vivo phase II metabolites and six in vitro phase I were found for vandetanib. Phase I metabolic pathways for vandetanib were $N$-demethylation, $N$-oxide formation, $\alpha$-carbonyl formation and $\alpha$-hydroxylation. All phase I metabolic pathways happened in $N$-methyl piperidine of vandetanib (Fig. 10). Four cyano adducts were characterized. All metabolic and bioactivation reactions occurred in the $\mathrm{N}$-methyl piperidine part which causes toxicity and instability of vandetanib (Additional file 1). 


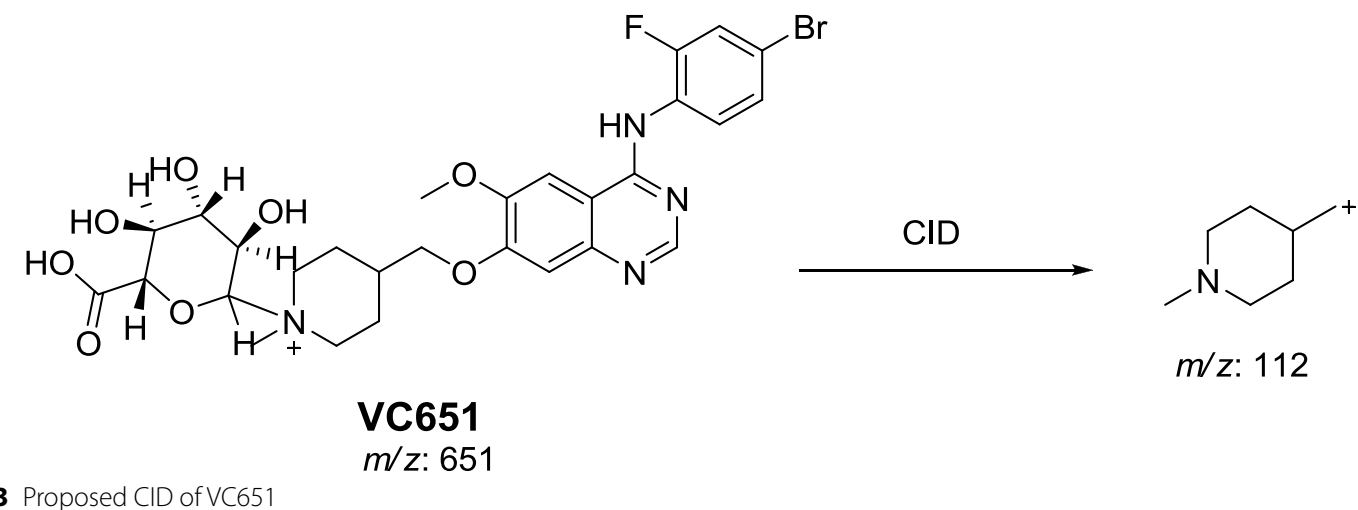

Scheme 13 Proposed CID of VC651

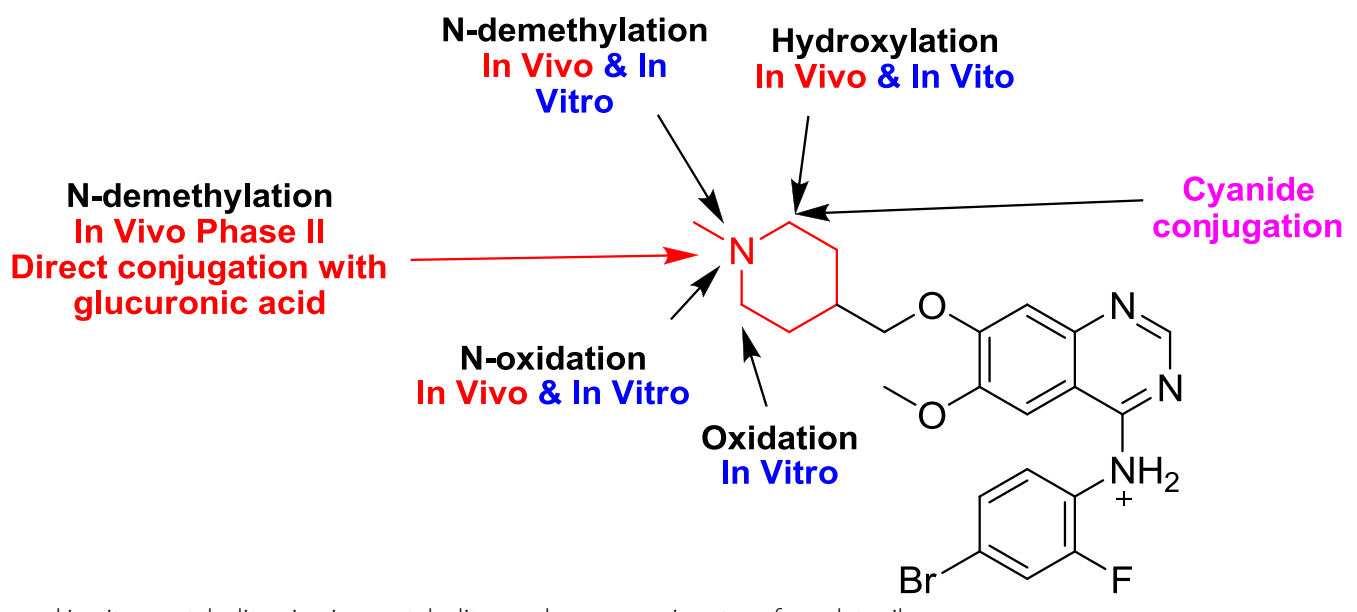

Fig. 10 Proposed in vitro metabolites, in vivo metabolites and cyano conjugates of vandetanib

\section{Additional file}

Additional file 1: Figure S1. PI chromatograms of molecular ions at $\mathrm{m} / \mathrm{z}$ 475 of organic extract of control urine sample taken before masitinib dosing showing no peaks at $58.3 \mathrm{~min}$. and $68.6 \mathrm{~min}$. Figure S2. PI chromatograms of molecular ions at $\mathrm{m} / \mathrm{z} 461$ of organic extract of control urine sample taken before vandetanib dosing showing no peak at $27.9 \mathrm{~min}$. Figure S3. PI chromatograms of molecular ions at $\mathrm{m} / \mathrm{z} 491$ of organic extract of control urine sample taken before vandetanib dosing showing no peak at 56.5 and 67.0 min. Figure S4. Product ion chromatogram of molecular ion peak at $\mathrm{m} / \mathrm{z} 475$ showing two peaks: VC491a (56.5 min) and VC491b (67.0 min). Figure S5. PI mass spectrum of molecular ion peak (vandetanib) at $m / z$ 475. Figure S6: PI mass spectrum of molecular ion peak (VC475) at $m / z 475$. Figure S7. Product ion chromatogram of molecular ion peak at m/z 461 showing one peak: VC461 (57.2 min). Figure S8. PI mass spectrum of molecular ion peak (VC461) at m/z 461. Figure S9. Product ion chromatogram of molecular ion peak at $m / z 491$ showing two peaks: VC491a (56.5 min) and VC491b (67.0 min). Figure S10. PI mass spectrum of molecular ion peak (VC491a) at $\mathrm{m} / \mathrm{z}$ 491. Figure S11. PI mass spectrum of molecular ion peak (VC491b) at m/z 491

\section{Authors' contributions}

MWA AAK, HWD, and SMA established the experimental design. MWA run the research. MWA, HWD, SMA and AAK analyzed the data. HWD, NSA and MWA wrote the first draft of the manuscript. SMA, AAK and NSA contributed in editing the language of the manuscript. SMA, HWD and AAK follow up the research steps. NSA made proofreading of the manuscript. All authors read and approved the final manuscript.

\section{Author details}

1 Department of Pharmaceutical Chemistry, College of Pharmacy, King Saud University, P.O. Box 2457, Riyadh 11451, Kingdom of Saudi Arabia. ${ }^{2}$ Analytical Chemistry Department, Faculty of Pharmacy, Cairo University, Kasr El-Aini St, Cairo 11562, Egypt.

\section{Acknowledgements}

The authors would like to extend their sincere appreciation to the Deanship of Scientific Research at the King Saud University for funding this work through the Research Group Project No. RGP-322.

\section{Competing interests}

The authors declare that they have no competing interests.

\section{Ethics approval and consent to participate}

Animal Care Center Guidelines at College of Pharmacy of King Saud University were followed. Use Committee and Local Animal Care of King Saud University approved maintenance of rats.

\section{Publisher's Note}

Springer Nature remains neutral with regard to jurisdictional claims in published maps and institutional affiliations. 
Received: 28 January 2018 Accepted: 19 September 2018

Published online: 24 September 2018

\section{References}

1. Martin P, Oliver S, Kennedy SJ, Partridge E, Hutchison M, Clarke D et al (2012) Pharmacokinetics of vandetanib: three phase I studies in healthy subjects. Clin Ther 34(1):221-237

2. Li F, Jiang S, Zu Y, Lee DY, Li Z (2014) A tyrosine kinase inhibitor-based high-affinity PET radiopharmaceutical targets vascular endothelial growth factor receptor. J Nucl Med 55(9):1525-1531

3. Thornton K, Kim G, Maher VE, Chattopadhyay S, Tang S, Moon YJ et al (2012) Vandetanib for the treatment of symptomatic or progressive medullary thyroid cancer in patients with unresectable locally advanced or metastatic disease: U.S. Food and Drug Administration drug approval summary. Clin Cancer Res 18(14):3722-3730

4. Kumar GN, Surapaneni S (2001) Role of drug metabolism in drug discovery and development. Med Res Rev 21(5):397-411

5. Evans DC, Watt AP, Nicoll-Griffith DA, Baillie TA (2004) Drug-protein adducts: an industry perspective on minimizing the potential for drug bioactivation in drug discovery and development. Chem Res Toxicol 17(1):3-16

6. Kalqutkar AS, Dalvie DK, O'Donnell JP, Taylor TJ, Sahakian DC (2002) On the diversity of oxidative bioactivation reactions on nitrogen-containing xenobiotics. Curr Drug Metab 3(4):379-424

7. Boelsterli UA (2002) Xenobiotic acyl glucuronides and acyl CoA thioesters as protein-reactive metabolites with the potential to cause idiosyncratic drug reactions. Curr Drug Metab 3(4):439-450

8. Knowles SR, Uetrecht J, Shear NH (2000) Idiosyncratic drug reactions: the reactive metabolite syndromes. Lancet 356(9241):1587-1591

9. Ju C, Uetrecht J (2002) Mechanism of idiosyncratic drug reactions: reactive metabolites formation, protein binding and the regulation of the immune system. Curr Drug Metab 3(4):367-377

10. Masic LP (2011) Role of cyclic tertiary amine bioactivation to reactive iminium species: structure toxicity relationship. Curr Drug Metab 12(1):35-50 (Epub 2011/01/13)

11. Zhang Z, Chen Q, LiY, Doss GA, Dean BJ, Ngui JS et al (2005) In vitro bioactivation of dihydrobenzoxathiin selective estrogen receptor modulators by cytochrome P450 3A4 in human liver microsomes: formation of reactive iminium and quinone type metabolites. Chem Res Toxicol 18(4):675-685

12. Park BK, Boobis A, Clarke S, Goldring CE, Jones D, Kenna JG et al (2011) Managing the challenge of chemically reactive metabolites in drug development. Nat Rev Drug Discov 10(4):292-306
13. Ma S, Zhu M (2009) Recent advances in applications of liquid chromatography-tandem mass spectrometry to the analysis of reactive drug metabolites. Chem Biol Interact 179(1):25-37

14. Stepan AF, Walker DP, Bauman J, Price DA, Baillie TA, Kalgutkar AS et al (2011) Structural alert/reactive metabolite concept as applied in medicinal chemistry to mitigate the risk of idiosyncratic drug toxicity: a perspective based on the critical examination of trends in the top 200 drugs marketed in the United States. Chem Res Toxicol 24(9):1345-1410

15. Salvador A, Vedaldi D, Brun P, Dall'Acqua S (2014) Vandetanib-induced phototoxicity in human keratinocytes NCTC-2544. Toxicol In Vitro 28(5):803-811

16. von Jagow R, Kampffmeyer $H$, Kinese M (1965) The preparation of microsomes. Naunyn-Schmiedebergs Archiv für experimentelle Pathologie und Pharmakologie 251(1):73-87

17. von Jagow R, Kampffmeyer H, Kiese M (1965) The preparation of microsomes. Naunyn-Schmiedebergs Archiv fur experimentelle Pathologie und Pharmakologie. 251(1):73-87 (Epub 1965/06/01)

18. Kadi AA, Attwa M, Darwish HW (2018) LC-ESI-MS/MS reveals the formation of reactive intermediates in brigatinib metabolism: elucidation of bioactivation pathways. RSC Adv 8(3):1182-1190

19. Amer SM, Kadi AA, Darwish HW, Attwa MW (2017) Identification and characterization of in vitro phase I and reactive metabolites of masitinib using a LC-MS/MS method: bioactivation pathway elucidation. RSC Adv 7(8):4479-4491

20. Kadi AA, Darwish HW, Attwa MW, Amer SM (2016) Detection and characterization of ponatinib reactive metabolites by liquid chromatography tandem mass spectrometry and elucidation of bioactivation pathways. RSC Adv 6(76):72575-72585

21. Shin J-W, Seol I-C, Son C-G (2010) Interpretation of animal dose and human equivalent dose for drug development. J Korean Med 31(3):1-7

22. Nair AB, Jacob $S$ (2016) A simple practice guide for dose conversion between animals and human. J Basic Clin Pharm 7(2):27-31

23. Reagan-Shaw S, Nihal M, Ahmad N (2008) Dose translation from animal to human studies revisited. FASEB J 22(3):659-661 (Epub 2007/10/19)

24. Argoti D, Liang L, Conteh A, Chen L, Bershas D, Yu C-P et al (2005) Cyanide trapping of iminium ion reactive intermediates followed by detection and structure identification using liquid chromatography-tandem mass spectrometry (LC-MS/MS). Chem Res Toxicol 18(10):1537-1544

25. Kadi AA, Amer SM, Darwish HW, Attwa MW (2017) LC-MS/MS reveals the formation of aldehydes and iminium reactive intermediates in foretinib metabolism: phase I metabolic profiling. RSC Adv 7(58):36279-36287
Ready to submit your research? Choose BMC and benefit from:

- fast, convenient online submission

- thorough peer review by experienced researchers in your field

- rapid publication on acceptance

- support for research data, including large and complex data types

- gold Open Access which fosters wider collaboration and increased citations

- maximum visibility for your research: over 100M website views per year

At BMC, research is always in progress.

Learn more biomedcentral.com/submissions 